\title{
Teaching Exploration of the Features of the Context-based Enterprise Management Course
}

\author{
Haihuai He \\ Wenzhou Vocational \& Technical College, Zhejiang, China, 325035 \\ 374183657@qq.com
}

\begin{abstract}
This paper analyzes the background of enterprise management course in vocational college. describes the "lead case, task-driven, strengthen training" teaching content which includes: the development of learning areas, creation of a dynamic update of teaching content system, the development of career action skills' training projects, improvement of the focus of skills training, scientific study of design tasks, school-enterprise cooperate to compile vocational action competence-oriented teaching materials, enrich classroom network, three-dimensional realization of curriculum teaching resource sharing. Further interpretation of the teaching is mainly to solve the problem, features and innovation, application and effectiveness. Problems and continue to improve measures to provide reference for Economic Management Course teaching situational characteristics. By using this feature, it can make the students gets self-motivated. Also the students would get more from the context-based enterprise management course, because they can get more experience during the process of the course. And makes the material learned in class can be connected with the future work in an enterprise.
\end{abstract}

\section{Key word: Context, Exploration, Task, Training, Enterprise management foundation course.}

\section{Introduction}

Traditional teaching model of Enterprise management course emphasizes the systematic curriculum knowledge. So that the learning process students should have - doubts, choose, critique, exploration, imagination, and creating are missing. Because of the mandatory learning content, passive cognitive activity-dependent process of thinking, single way of classroom communication, it ignores the students' enthusiasm, initiative learning. So overall, students are lack independent learning ways of learning and research. Teaching activities missing a relaxed, pleasant, democratic, harmonious and high evaluation, high motivation psychological environment. And the supports for innovation learning is not enough which cause it is difficult effectively learn and master the experiential knowledge and strategic knowledge is difficult during in the work process.

Meanwhile, the practice-based arrangements discipline system is often difficult to compare the broadly needs of the future course of action of professional positions in the action projects and operational tasks. Ignored to create the practical projects and action situations in practice, and do not consider student' s occupation in real life: employee-manager- general manager. The Usage of skills started from the most basics, and gradually integrated use of multiple skills to form the skill using pattern. And makes students hard to have a complete course of action experience. Thus, it cost students lack of professional consciousness, and do not have a clear learning objectives.

"Enterprise Management Foundation" is a specialized professional competence core curriculum in business management major. It plays an important role in business management professional teaching, and should provide a guarantee and promote the smooth implementation of the later follow-up courses. Curriculum should meet the high-skilled personnel training objectives and professional positions' requirements and can play a major support or significant role in promoting for students to develop vocational action competence and professionalism. The situational teaching ideas used in "Enterprise Management" course teaching should be very attractive challenge. Case led, task-driven, strengthen training, "teaching, learning, thinking, and doing" four in one "Enterprise Management Foundation" exploring situational teaching. Implementation of "lesson, certificate, job" integration of teaching, the establishment of multi-channel, Obtain Large Teaching Systems still hard to see. 


\section{Teaching Features Exploration}

Build enterprise management vocational action competency framework according to the demand for professional occupation; Revise talent training program, establish a business management curriculum standards that is scientific and rational; implement task-oriented, developing area of study, teaching scene design; Constructivism is based on the development of design student-centered "situation" teaching-learning-pack; to mobilize the enthusiasm of the students as the core, the establishment of multi-channel, obtain teaching mode large teaching system; the use of heuristic teaching to guide and enhance the situational teaching, strengthen students' future social work adaptability; reasonable structure teaching team with, enrich teaching resources, improve the quality of teaching; actively use modern educational technology to improve education standards and expand the amount of information teaching; actively implement the "lesson, certificate, job" integration of teaching, organizing students to obtain "General management" professional qualifications.

\subsection{Development Area of Study, Establish a Dynamic Update of Teaching Content System}

According to Students Career Action Ability of the basic pattern, use vocational ability to act as a guide to further sort out the contents of the framework and teaching the concept of corporate management foundation courses. The development of learning area forms eight teaching scenarios which are: "Scenario 1: business and environmental analysis, Scenario 2: Management and managers, Scenario 3: The development of management theory, Scenario 4: business goals and plans, Scenario 5: scientific decision-making and strategy, Scenario 6: structure and change, Scenario 7: leadership methods and art, Scenario 8: control the process and methods.

Curriculum content should be reasonable. Makes the course content and the corresponding level management positions consistent with the comprehensive management skills. Start from the analysis of the professional positions, and develop vocational ability to act as the main line, select course content reflects the characteristics of higher vocational education. Create dynamic update of "126" teaching content system, which has "one main line", "two basic foundation", and "six key abilities" . "One main line" means training integrated management skills to chief management positions as the main line. The first of the "Two basic foundation" is the basic knowledge of management and the second one is the basic theory of management. "Six key abilities" are Enterprise environment analysis capabilities, Target management and planning capabilities, Decision-making ability and strategic choice, Organizational design and coordination, Leadership and motivation communication skills, Control and information processing capacity. And these elements forms the " 126 " teaching content system.

\subsection{The Development of Vocational Training Programs Operational Capacity, Improve the Focus of Skills Training}

For enterprise management of the eight teaching scenarios, start with the analysis of the professional positions, and then determine the content of skills training courses. Forms vocational training project is typical operational capacity that can use both to the basics of the application management scenario and basic theory. To be able to fully reflect the chief management positions' integrated management skills, improve skills training focus. And design a logical teaching process. The ability to draw a diagram culture, teaching and task flow chart diagram animation. 


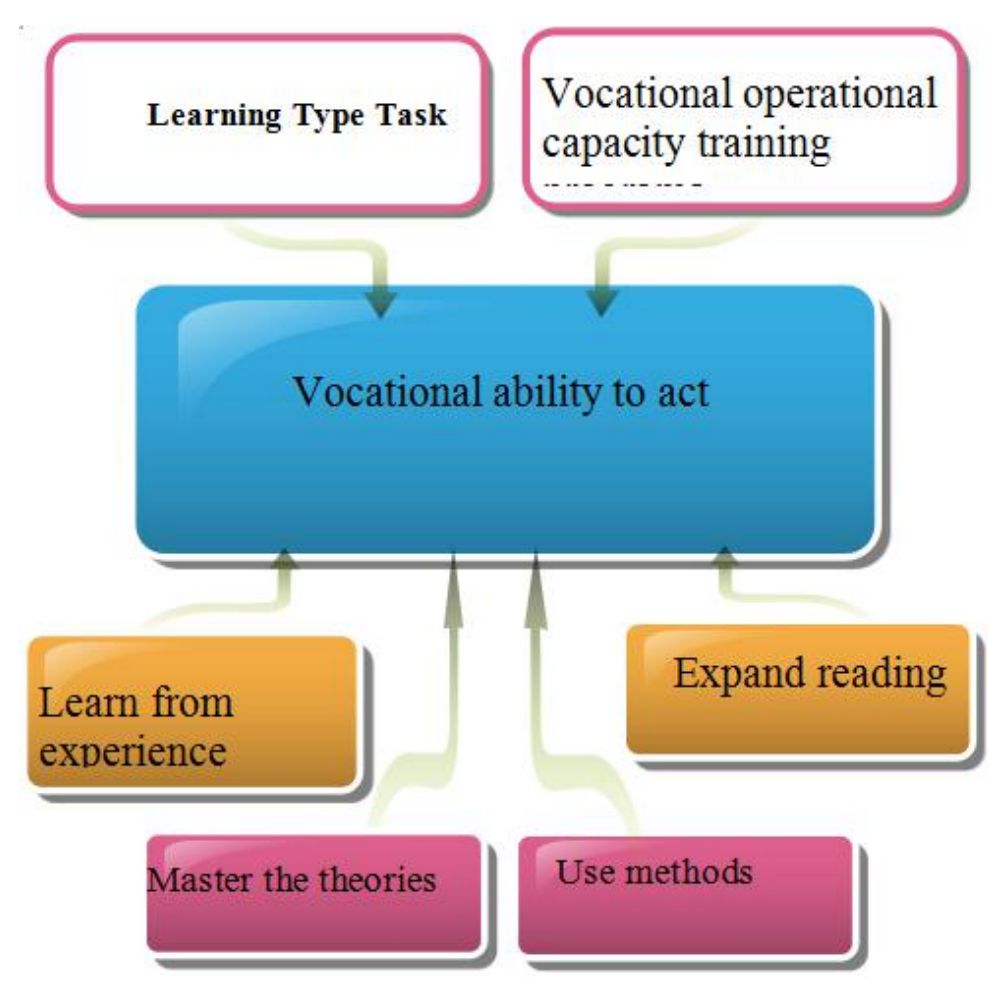

Figure 1. Sketch for each ability scene

Case led, task-driven, strengthen training, "teaching, learning, thinking, doing" four in one, each scene Ability diagram shown in Figure 1 and each scenario Ability drawings see textbook "Enterprise Management Infrastructure ( $2^{\text {nd }}$ Edition)". Teaching process design, enhanced vocational training capacity for action. Draw flowcharts and teaching mission animation FIG. Each scene teaching flowcharts and each scenario task animation drawings can be found in the "Enterprise Management Fundamentals" course website.

\subsection{Scientific Design of Study Tasks}

Develop and improve the basic curriculum construction documents, such as curriculum standard, instructional design, teacher's guide, self-study guide, teaching plan, multimedia courseware; combing knowledge of the eight teaching scenarios, focus on organize the key concepts, theories and management methods, and made famous expert rostrum, knowledge schematic drawing; organize business management experience in practice and collect important case of corporate management , corporate management electronic books, recommended books list, interest reading, for students to read; design a logical teaching evaluation methods, the development of process assessment exam, let students do self-test or evaluation of teaching content relevant to teaching situation, and enhance students' self-learning ability to stimulate student interest in learning.

- Teaching Guide

$\circ$ Teaching design

- Teacher directs

- Self-taught instruction

- Ability raise chart

- Teaching flow chart

- Duty animation demonstration chart

- Teaching lesson plan, Multimedia courseware

- Practical experience, Development reading

- Electron books

○ Recommended book list

- Interest reading

- Knowledge spot, Case analysis 
○ Essential concept

- Correlation theories

- Management methods

- Famous expert introducing

○ Knowledge schematic drawing

- Teaching video frequency

- Course introduction

o Teaching video recording

O Report exchange

- Training video recording

- Famous expert rostrum

- Process inspection

- Concept problems

- Multiple choice questions

- True of False questions

- Short answer questions

o Skill Testing

- Integrated case analysis

- Active design

- Practical activity

- Management games

- Team cooperation

- Case analysis

Constructivism as the basis, the necessary for limit, and makes a good balance between the teachers teaching and students learning. Binding the curricular and extracurricular teaching, enhance lessons teaching structure and teaching process, innovative education model to enhance the level of teaching and the quality of teaching, provide a full range of solutions to this curriculum oriented.

2.4 Build a School-enterprise Cooperation, to Prepare Vocational Action Competence-oriented Teaching

According to curriculum standards, cooperation with other vocational institutions, industries and enterprises, in order to prepare vocational action competence-oriented "the basics of enterprise management" Teaching materials (including electronic edition). In cooperation with SMEs (small and medium enterprise) in Wenzhou, compiled the Wenzhou business management case comprehensive work, as part of the situational teaching resources, but also as a business management professional thesis reform, held biography case Study competition.

Closely integrated teaching and curriculum reform, fully learn the outcome of Vocational Teaching Reform of Economic Management, according to the main line of vocational skills training, knowledge for the preparation of thinking organization supporting the preparation of teaching materials, fully embodies the field of business management new ideas, new tools, new methods to deal with the theoretical teaching relationship skills training, effective implementation of "Practicality, enough for" teaching guiding ideology, and a three-dimensional construction of resource planning, enterprise and the latest theoretical achievements case management applied to textbooks, there should be some innovation and improvement.

\subsection{Enrich Network Classroom Curriculums Realize Resource Sharing}

Scientific and rational development of micro-lesson curriculum teaching videos shot and uploaded to the course website to help independent learning. Focus on students 'self-learning and collaborative learning network. The site offers an interactive platform for teachers and students, and set up an online testing system, discussions forum, homework submission correcting system, and these greatly facilitate the students' independent learning, and adds interaction between teachers and students. It also set up a "professional qualification" and the daily updates of "daily enlighten". And also, to improve students' interest in learning, the websites set up "easy test", "famous lecture", "hundred enterprises ". Continuously enriched content in network classroom, and shares all of the curriculum 
teaching resources in Internet; in the application process context-based teaching resources in perspective, identify problems, and constantly improve and perfect the specific content of curriculum standards, three-dimensional teaching resources.

\section{Teaching Main Problem Solved}

Teaching ideas used in the context of enterprise management Vocational Teaching practice should be very attractive challenge and exploration, and this mainly to solve the teaching problem are:

(1) Study of enterprise management infrastructure Course has the dynamic and complex nature of the characteristics and pattern. In modern day which the Vocational education emphasizes the action-oriented teaching, based on the use of general principles of good teaching theory, actively study and understand the principles of teaching economic theory and applied to the course teaching practice. And to establish a scientific and rational enterprise management curriculum standards.

(2) Use professional positions as guide line, fully reflect the integrated management positions in order to cultivate grassroots management skills as the main line, so that students master the basic management knowledge and management theory, and train students to have those six key vocational ability.

(3)Ability to act according to the needs of the Vocational, the formation of the skills training program is typical. Improve skills training focus to national occupational standards as the basis, teaching covering the relevant requirements, and makes the "double certificates" system in implementing the teaching and implementation to improve their employability and sustainability

(4) leading case, task-driven, strengthen training, "teaching, learning, thinking, doing" four in one, in order to motivate students as the core, in order to simulate the practice of teaching the main line, to build a multi-channel context to get Obtain Large Teaching Systems, to enhance students' learning autonomy and create a wide range of teaching channels to promote the improvement of the overall quality of students.

(5) break the traditional disciplinary system to better deal with the relationship between theory and teaching skills training, practical implementation of the "useful, good enough for" teaching guiding ideology; fully reflect the field of business management in the new knowledge, new technology, new method, in order create the conditions to improve students' employability and sustainable development.

\subsection{Characteristics and Innovation}

(1) "situation" teaching-learning-packet (TLP), training professional capacity to act. Constructivism as the basis, designed to develop student-centered "situation" teaching package, to create a dynamic update of "126" teaching content system, fully reflects the chief management positions to develop integrated management skills as the main line enable students to master the basic theory and basic knowledge of management, and train students six key vocational ability.

(2) lead case, task-driven, strengthen training, financial "teaching, learning, thinking, doing" four in one. Scientific study of design tasks, to be able to fully reflect the grass-roots level management positions in comprehensive management skills, and the rational design of teaching process, the ability to draw a diagram culture, teaching and task flow chart diagram animation, task-oriented closed-loop take teaching.

(3) Multi-channel access, to enhance students' learning autonomy. Design and build multi-channel, Obtain Large Teaching Systems, with strong structural and operability, enhance the students' learning autonomy and the creation of a wide range of teaching channels to promote the improvement of overall quality of students.

\subsection{Continue to Improve}

(1)Build a better teaching staff team, and support teachers to participate in international academic exchanges, and strengthen the research of teaching reform, deployed at corporate training of teachers, improve the practical ability to operate and provide good social services for enterprises;

(2) In the actual teaching process to improve the teaching video, and to further develop and improve the basic curriculum construction documents, such as standard curriculum, instructional design, teacher's guide, self-study guild; 
(3) The construction of three-dimensional materials, business management classic case of libraries and vocational action competence training programs, increase the use of course websites, online teaching and other modern teaching methods and technology;

(4) Enriched content network classroom, curriculum teaching resources to achieve all the Internet sharing, good connotation construction intramural productive training base, and industry experts to discuss and jointly determine the internal and external training programs and internships environment, continue to build a number of well-known off-campus practice base.

Overall, the subsequent construction of the course, the focus is on improving teaching methods, teaching content optimization, teachers strive to have a new breakthrough on the increase.

\section{Conclusions}

The core idea of situational teaching is that students have to motivate himself behind the learning process. Students will be based on their own original experience to construct knowledge. The educators' responsibility is to create a situated learning environment for students. During the process of creating the situation, technology, especially Internet technology can play an important role and makes it possible to do the online collaborative learning across time and space.

Case led, task-driven, strengthen training, "teaching, learning, thinking, doing" four in one "enterprise management foundation" situational teaching, and give this course provides a full range of solutions. It can satisfy the teachers' needs for teaching and students' independent learning needs, and it enhance the teaching normatively and learning independently. Fully usage of modern educational technology, to create a wide range of teaching channels, a full range of teaching resources to support system transformation, and that can better enhance the quality of education.

\section{Reference}

[1] Biao Li, Jihua Cao, Baoming Hao. Exploration [J] PLC task driven method in teaching; Chifeng University (Natural Science); 201218

[2] Fengxiang Xiao, Xianhui Dong. Occupation of the Regulations to the vocational education curriculum [J]; Chinese Vocational and Technical Education; 201121

[3] Liang Zhang. Professional Quality Standard of Higher Education Curriculum Building of [D]; Hunan Normal University; 2012

[4] Yuhong Cao. Research in the digital environment Situational teaching mode of vocational education $[\mathrm{J}]$; Chinese information technology education; 201407

[5] Jian Ma, Zhouxiu Wang, Yafeng Xu. The Future of Design and application of classroom learning experience [J]. Educational research 2013 05;

[6] Yaodong Hu, Hongli Yao. Research on Digital Campus Online Learning [J]; Anhui Electrical Engineering Professional Technique College; 201302

[7]Zijian Wang, Yuzhen Wang. Dongli Chen. In vocational competency-based modular curriculum system construction[J].

[8] Ying Chen. Analysis of the information technology classroom teaching situations set [J]; Fujian College of Education; 201403

[9] Xi Dong. To "work scenario" oriented Higher Vocational Practice Teaching Mode of Basic Accounting [A]; 2011 Wuxi Vocational Education Teachers Forum Proceedings [C]; 2012

[10] Yao Xinqin;; Research on reform of college action-oriented method [J]; China Adult Education; 201324 